\title{
The significance of rhinomanometry in evaluation of postlaryngectomy olfactory rehabilitation by polite yawning technique*
}

\author{
Dubravko Manestar ${ }^{1}$, Robert Tićac ${ }^{1}$, Marko Velepič ${ }^{1}$, Tamara Braut ${ }^{1}$, Ines Manestar \\ Donadić $^{2}$, Koraljka Manestar ${ }^{3}$, Goran Malvić ${ }^{1}$, Radan Starčević ${ }^{1}$ \\ 1 Department of Otorhinolaryngology, Head and Neck Surgery, Clinical Hospital Centre Rijeka, Rijeka, \\ Croatia \\ 2 Department of Ophthalmology, Clinical Hospital Centre Rijeka, Rijeka, Croatia \\ 3 Department of Pediatrics, Clinical Hospital Centre Rijeka, Rijeka, Croatia
}

SUMMARY

\begin{abstract}
Objective: To corroborate the result of postlaryngectomy olfactory rehabilitation evaluating the efficacy of the Polite Yawning Technique (PYT) with rhinomanometry and odours with the Smell diskettes Olfaction test (SDOT).

Materials and methods: Thirty-two laryngectomised patients were subjected to olfactory rehabilitation consisting of 15-minute training and independent exercising for two weeks. The sense of smell and nasal airflow in laryngectomised patients were examined before and after implementation of PYT.

Results: The differences in SDOT results prior to and after introduction of PYT were statistically significant, most patients achieving better results after rehabilitation. A significant positive correlation was obtained in results of SDOT and rhinomanometry prior to and after introduction of PYT. The results of measurements after rehabilitation showed that $75 \%$ of patients had improved nasal breathing, $78 \%$ of patients had a better sense of smell and $40 \%$ of patients became normosmic.

Conclusions: PYT has proved to be an effective method in olfaction rehabilitation following total laryngectomy. Using rhinomanometry, evaluation of the rehabilitation success is substantiated while the technique is simplified.
\end{abstract}

Key words: olfactory rehabilitation, Polite Yawning, rhinomanometry, Smell Diskettes Olfaction Test, laryngectomy

\section{INTRODUCTION}

Following total laryngectomy, patients no longer breathe through the nose but through a tracheostoma. In this way, the olfactory region in the nose is bypassed and the sense of smell is lost.

The importance of the sense of smell is realised only when it is lost (1). Without olfaction, food and drink lose part of their taste ${ }^{(2)}$. The inability to detect smoke or dangerous gases increases the feeling of fear and exposes us to danger. The inability to be aware of one's own body odour causes insecurity and excessive use of perfume, excessive cleaning and showering. Even libido and sexual activity have been shown to be reduced ${ }^{(3,4)}$.

To achieve a better quality of life for laryngectomised patients, olfactory rehabilitation should be undertaken as soon as possible. Airflow through the nose must be established once again, and with it the sense of smell. What had previously been an automatic action must now be consciously and actively performed. One of the methods of rehabilitating the sense of smell is the Nasal Airflow - Inducing Maneuver ('Polite Yawning') ${ }^{(5)}$. This has proven to be a successful method ${ }^{(6)}$, although it is dependent on the patient's cooperation and factors over which doctors have no influence. Smoking (7), age and environmental factors not only have impact on the development of laryngeal carcinoma, but also cause degeneration of the olfactory epithelia with consequent hyposmia or anosmia.

\section{MATERIALS AND METHODS \\ Patients}

Members of the Laryngectomised Patients' Club sponsored by the Clinic of Otorhinolaryngology, Head and Neck Surgery KBC Rijeka, participated in the study. The Club meetings are held twice a month and attendance is voluntary. All patients who attended the lecture on the importance of Olfactory Rehabilitation were included in the study. The study 


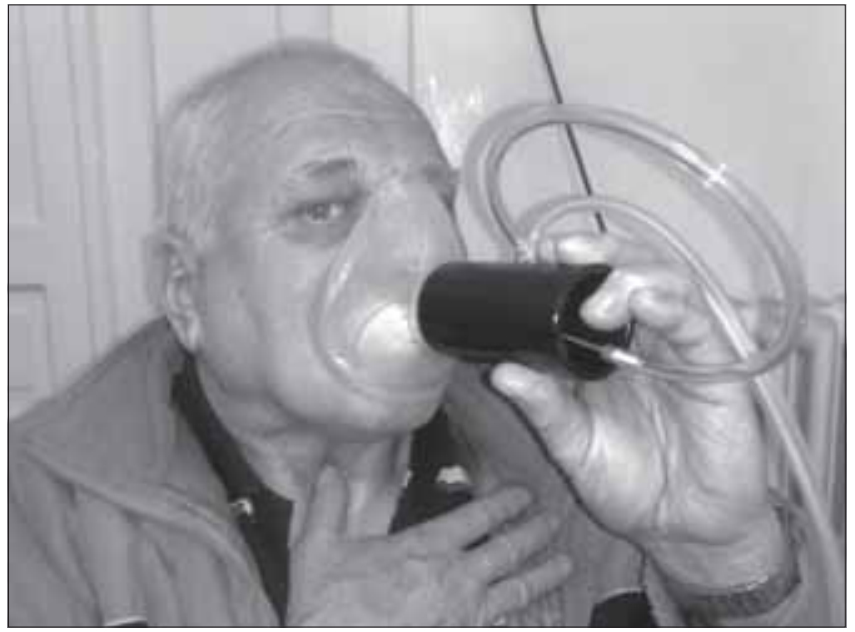

Figure 1. Laryngectomised patient using a rhinomanometer.

population comprised 29 men (91\%) and 3 women (9\%). The mean age was $60.81 \pm 7.92$ years, ranging from 48 to 75 years. The interval duration following total laryngectomy was from 6 months to 12 years, with an average of $3.19 \pm 3.11$ years. Prior to study enrolment, endoscopic evaluation was carried out and all patients in whom we could not assess the olfactory groove endoscopically were excluded from the study. All patients gave their informed consent and the study was approved by the Medical-Ethical Protocol Institutional Review Board.

\section{Olfactory rehabilitation}

The objective of PYT is to establish airflow through the nose by creating negative pressure in the oral cavity and oropharynx. The theory of PYT was explained to the subjects in a 10-minute session during group meetings. The practical part of carrying out the technique was explained individually during a period of approximately 5 minutes. The technique includes getting the patient to yawn with closed mouth. The lips are kept closed while at the same time the jaw, floor of the mouth, tongue, base of the tongue and soft palate are lowered ${ }^{(8)}$. The movements must be quickly repeated several times to achieve maximal effect. The patients practice the technique for 2 weeks at home. This time period was chosen since we estimated that patients may lose interest afterwards.

\section{Active anterior rhinomanometry}

Rhinomanometry is a dynamic and objective method ${ }^{(9,10)}$. Its purpose is to measure nasal airflow, pressure and resistance in the nostrils ${ }^{(1)}$. Active anterior rhinomanometry (AAR) measures the pressure difference between the nasal entrance and the choane. In AAR, one nostril is closed with a measuring pressure probe, while the other nostril is used for rhinomanometric measuring ${ }^{(12)}$. It provides relevant data of nasal flow in relation to the respiratory activity being carried out by the patient. The curves of the air volume seen on the monitor of the rhinomanometer give direct visual feedback. Simultaneous display of the pressure-flow curve is provided so if the mask leaks or other problems with data collection occur, they can be detected during the test. In the study, the
Rhinomanometer 300 (Atmos, Lenzkirch, Germany) was used. AAR was employed while the patient performed PYT to measure its effectivity on results of nasal inspiration. The applied technique was standard ${ }^{(10)}$, apart from the fact that the patient held the mask with one hand while closing the stoma with the other. The purpose of this was for the patient to concentrate on the technique and avoid hyperventilation ${ }^{(13)}$ (Figure 1). We evaluated the results of the rhinomanometric measurements with 0,1 and 2 (Figures 2A-C). Zero was defined as a measurement without any airflow, 2 as a measurement with measurable airflow and numeric value. One represented an intermediate value: airflow was detected on the graph curve but was insufficient (not transpassing the dotted vertical line) to be numerically evaluated by the rhinomanometer computer processor.

\section{The Smell Diskettes Olfaction Test}

The Smell Diskettes Olfaction Test (SDOT) is a screening test designed to show whether the sense of smell is functioning properly or not. The test consists of 8 reusable diskettes with different odours (coffee, vanilla, peach, grass, pineapple, rose, chocolate and fish). The patient had to choose one of three answers provided for each smell. The fragrances were contained in special cassettes and opened by the patients themselves. Cassettes were placed beneath the nostrils and the odour inhaled. For each correct answer subjects got 1 point from a maximum of 8 . A result of 7 or 8 points represents normal olfactory function, while 6 or less indicates hyposmia, anosmia or lack of cooperation. The possibility of an anosmic individual achieving 7 or 8 correct answers is $0.26 \%{ }^{(14,15)}$. To obtain a better concentration on the technique during olfactory testing, the patient held the cassette with one hand while closing the stoma with the other. The SDOT was chosen based on research performed by Hilgers et al. and its relatively simple application ${ }^{(8,22)}$.

\section{Statistical analysis}

All the data were evaluated by the Paired Samples t-test and $\chi^{2}$ test. Spearman's Correlation Coefficient was used because of the relatively small number of subjects and irregular distribution. Probability (p) values of less than 0.05 were regarded as significant. SPSS 16.0 for Windows (SPSS Inc, Chicago, IL, USA) was used for all analyses.

\section{RESULTS}

\section{Rhinomanometry results}

The first rhinomanometric measurement (R1) was marked " 0 " in 18 patients $(56.2 \%)$, " 1 " in 10 patients $(31.2 \%)$ and " 2 " in 4 patients $(12.6 \%)$. Rhinomanometric measurements were repeated after 15 -minute training and two-week individual practicing (R2). Two patients had a graph curve marked as " 0 " $(6.2 \%), 6$ patients had a graph curve " 1 " $(18.8 \%)$, while 24 patients had a graph curve " 2 " (75\%). Significantly improved rhinomanometric measurements (from score 0 to 2 ) were achieved in 12 patients $(37.5 \%)$, while 8 patients showed no change in their score $(25 \%)$ (Table 1$)$. When the relationship 
Table 1. Rhinomanometry results.

\begin{tabular}{lcccc}
\hline Rhinomanometry & \multicolumn{2}{c}{$\begin{array}{c}\text { Prior to rehabilitation } \\
\mathbf{N}\end{array}$} & \multicolumn{2}{c}{$\begin{array}{c}\text { After rehabilitation } \\
\mathbf{( \% )}\end{array}$} \\
\hline Finding type 0 & 18 & $(56.2)$ & 2 & $(6.2)$ \\
Finding type 1 & 10 & $(31.2)$ & 6 & $(18.8)$ \\
Finding type 2 & 4 & $(12.6)$ & 24 & $(75)$ \\
\hline
\end{tabular}

Finding type 0 - no airflow, no curve or numeric finding on graphic presentation.

Finding type 1 - airflow detected on the graph curve but without numeric value.

Finding type 2 - the curve of airflow with numeric value.

between rhinomanometric measurements was examined, the values in R1 did not significantly correlate with those in R2 $\left(r_{s}=0.26 ; p=0.151\right)$. Between R1 and R2 there was also no significant difference $\left(\chi^{2}\right.$ test $\left.=2.963 ; \mathrm{ss}=4 ; \mathrm{p}=0.564\right)$.

\section{Olfactory results}

Before the introduction of PYT, none of the patients had 7 or 8 correct answers in SDOT. After a repeated test, 3 patients $(9.4 \%)$ had all 8 answers correct and $10(31.2 \%)$ had 7 correct answers, allowing the conclusion that they achieved complete olfactory rehabilitation. Twenty-five patients (78.2\%) improved their test results (Table 2).

When the correlation between the scores achieved in SDOT1 and SDOT2 was examined (Smell Diskette Olfaction Test prior to and after rehabilitation), it was established that the scores in SDOT1 and SDOT2 had a high positive correlation $\left(r_{\mathrm{s}}=0.51\right.$; $p=0.003)$. Consequently, when the subjects achieved higher values in SDOT1 (guess smell), the values in SDOT2 were also higher.

Furthermore, the differences between SDOT1 and SDOT2 were examined and a statistically significant difference was obtained between them $(t=6.828 ; p<0.001)$. Most of the subjects achieved higher scores in the second measurement (SDOT2, $\mathrm{M}=5.72$ ) than in the first one (SDOT1, $\mathrm{M}=3.78$ ). It is interesting to note that none of the subjects had lower values in SDOT2 than in SDOT1.

\section{Comparison of rhinomanometry and olfactory results}

The relation between SDOT and rhinomanometry measurements was analyzed. A significantly positive correlation was obtained between SDOT 1 and R $1\left(r_{s}=0.64\right.$; $\mathrm{p}<0.001)$ and between SDOT2 and R2 $\left(\mathrm{r}_{\mathrm{s}}=0.54 ; \mathrm{p}=0.002\right)$. Consequently, when the values of rhinomanometry ( $\mathrm{R} 1$ and $\mathrm{R} 2$ ) were higher, the patients had better scores in the smell tests (SDOT1 and SDOT2), and vice versa (Table 3).

Comparison of peak inspiratory velocity at the pressure of $75 \mathrm{~Pa}$ and olfactory results

SDOT1 was not significantly connected with any analysed variable, while SDOT2 was significantly positively connected with F12 (Peak inspiratory velocity at the pressure of $75 \mathrm{~Pa}$ of the left nostril after rehabilitation) $\left(r_{s}=0.579 ; p=0.001\right)$ and Fr2 (Peak inspiratory velocity at the pressure of $75 \mathrm{~Pa}$ of

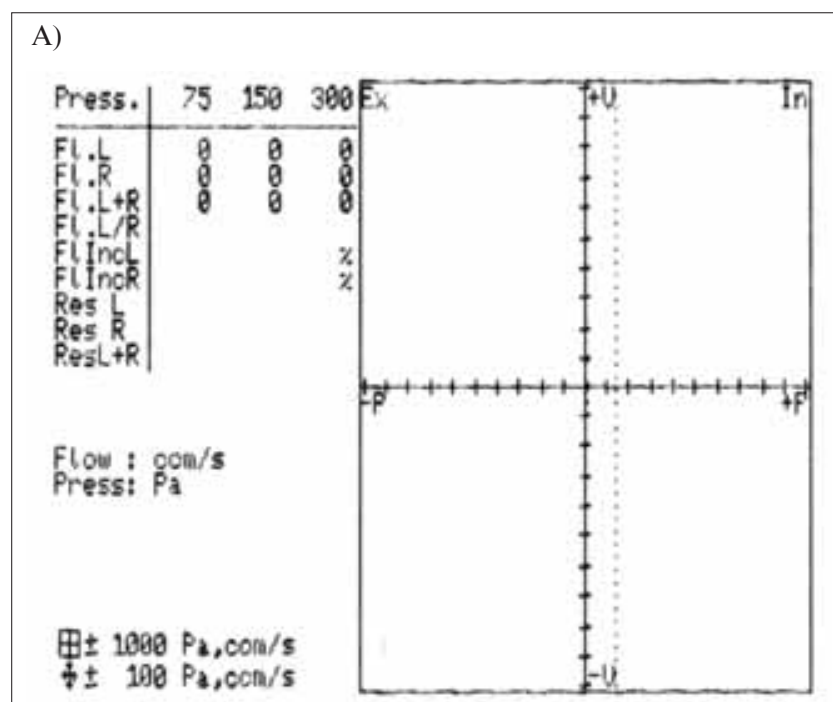

B)

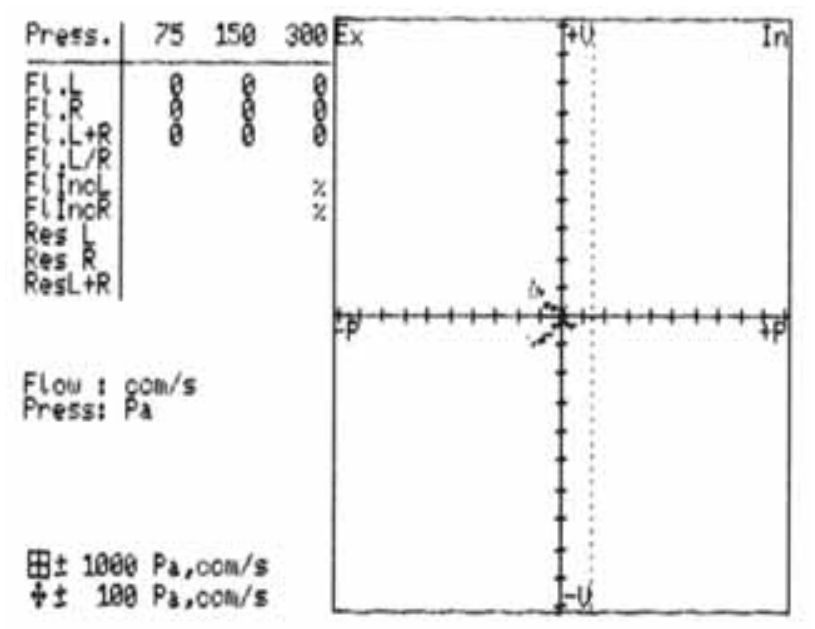

C)

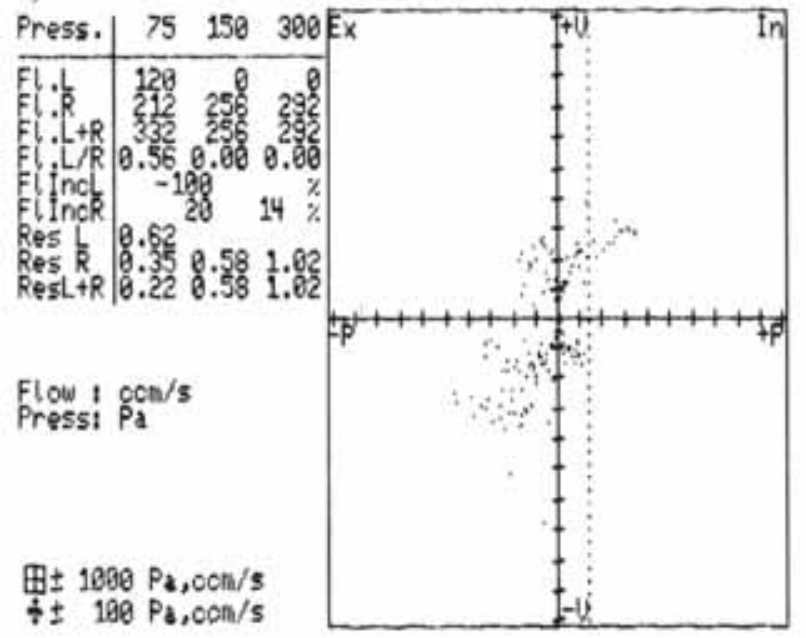

Figure 2. A) Rhinomanometric finding type 0. No airflow. No curve or numeric finding on graphic presentation. B). Rhinomanometric finding type 1. Airflow detected on the graph curve but without numeric value. C). Rhinomanometric finding type 2 . Shows the curve of airflow with numeric value. 
Table 2. Smell Diskette Olfactory Test (SDOT) results.

\begin{tabular}{|c|c|c|c|c|}
\hline \multirow{2}{*}{ Correct answers } & \multicolumn{2}{|c|}{ Prior to rehabilitation } & \multicolumn{2}{|c|}{ After rehabilitation } \\
\hline & $\mathbf{N}$ & $(\%)$ & $\mathbf{N}$ & $(\%)$ \\
\hline 0 & 1 & $(3.1)$ & 0 & $(0)$ \\
\hline 1 & 2 & $(6.3)$ & 0 & (0) \\
\hline 2 & 5 & (15.6) & 0 & $(0)$ \\
\hline 3 & 5 & $(15.6)$ & 3 & $(9.4)$ \\
\hline 4 & 8 & $(25)$ & 5 & (15.6) \\
\hline 5 & 4 & $(12.5)$ & 6 & (18.8) \\
\hline 6 & 7 & (21.9) & 5 & (15.6) \\
\hline 7 & 0 & $(0)$ & 10 & (31.2) \\
\hline 8 & 0 & $(0)$ & 3 & $(9.4)$ \\
\hline Mean \pm SD & \multicolumn{2}{|c|}{$3.78 \pm 1.70$} & \multicolumn{2}{|c|}{$5.72 \pm 1.53$} \\
\hline
\end{tabular}

Table 3. Correlation between Smell Diskette Olfactory Test (SDOT) and rhinomanometry measurements prior to (R1) and after rehabilitation (R2).

\begin{tabular}{lccl}
\hline & $\mathbf{R}_{\mathbf{s}}$ & $\mathbf{p}$ & $\mathbf{N}$ \\
\hline SDOT1 / R1 & 0.64 & 0.001 & 32 \\
SDOT1 / R2 & 0.01 & 0.938 & 32 \\
SDOT2 / R1 & 0.29 & 0.106 & 32 \\
SDOT2 / R2 & 0.54 & 0.002 & 32 \\
\hline
\end{tabular}

$r_{s}$ - Spearman's Correlation Coefficient.

Table 4. Correlation between Smell Diskette Olfactory Test (SDOT) and Peak inspiratory velocity at the pressure of $75 \mathrm{~Pa}$ of the left nostril (F11) and the right nostril (Fr1) prior to, and the left nostril (F12) and the right nostril (Fr2) after rehabilitation.

\begin{tabular}{lccc}
\hline & $\mathbf{r}_{\mathbf{s}}$ & $\mathbf{p}$ & $\mathbf{N}$ \\
\hline SDOT1 / F11 & 0.327 & 0.068 & 32 \\
SDOT1 / Fr1 & 0.315 & 0.079 & 32 \\
SDOT2 / F11 & 0.135 & 0.461 & 32 \\
SDOT2 / Fr1 & 0.123 & 0.503 & 32 \\
SDOT1 / F12 & 0.306 & 0.088 & 32 \\
SDOT1 / Fr2 & 0.263 & 0.146 & 32 \\
SDOT2 / F12 & 0.579 & 0.001 & 32 \\
SDOT2 / Fr2 & 0.572 & 0.001 & 32 \\
\hline
\end{tabular}

$r_{s}$ - Spearman's Correlation Coefficient.

the right nostril after rehabilitation) $\left(\mathrm{r}_{\mathrm{s}}=0.572 ; \mathrm{p}=0.001\right)$. Consequently, the higher the SDOT2, the higher were the values of F12 and Fr2 variables (Table 4).

Comparison of rhinomanometry and olfactory results with patient's age and time elapsed from surgery

Scores of all analysed variables were lower given the patient's age at a statistically significant level $(\mathrm{p}<0.05)$. Accordingly, the values of SDOT1, SDOT2, R1 and R2 were lower in older patients. Laryngectomy elapsed time was not significantly correlated to any other variable. These correlations were negative (the longer the treatment time, the lower the rhinomanometry scores $)\left(r_{s}=-0.23 ; p=0.212\right.$ with SDOT1 and $r_{s}=-0.26 ; p=0.151$ with SDOT2), but without statistical significance. The number of patients was relatively low, letting us assume that in a larger sample, these correlations would probably be statistically significant.

\section{DISCUSSION}

This study evaluates the capacity to improve the possibility to perceive odours post laryngectomy by training PYT. Smell disorders are generally differentiated into sensorineural and conductive ones. Using endoscopy, we aimed at excluding subjects with conductive smell disorders, while expecting the majority to have normal sensorineural capacity to sense odour. A drawback of our study is the missing olfactory testing prior to laryngectomy to prove this assumption. Due to recently reported anosmia incidence of $5.8 \%$ in an epidemiological study in Sweden ${ }^{(16)}$, we have to admit that a proportion of our non-responders to treatment may actually suffer from undetected sensorineural loss of smell. This issue should be evaluated in a prospective study. It should be pointed out that the authors adhered to SDOT criteria for normal olfactory sensitivity (7 or 8 of the odours scored correctly). Some of the patients achieved fewer than 7 correct answers and could be considered to some extent hyposmic, which might lead to an underestimation of olfactory rehabilitation results. SDOT is a subjective method and as such dependent on the patient's cooperation. One of the patient's remarks regarding SDOT was that although sensing odours, they were unable to confidently identify them, even if in authentic situations they found it easier to recognize odours. Another important patient's observation related to the saturation of olfactory receptors by a previous odour or some other fragrance in the immediate vicinity, which prevented recognition of the fragrance provided.

Rhinomanometry is a fast and relatively simple method that describes the volume and speed of inhaled and exhaled air and gives an objective state of nasal airflow. Simultaneous display of the pressure-flow curve is provided so that not properly performed PYT or mask leaks can be detected during the test and corrections made accordingly in real time. Adjustments in real time, from our experience, simplified and enhanced technique explanation to the patient, compared to standard olfactory rehabilitation carried out at our clinic ${ }^{(17)}$. In a review of available literature data, we were unable to find applications of rhinomanometry in the evaluation of olfactory rehabilitation success in laryngectomised patients ${ }^{(18,19)}$.

For rehabilitation of their patients some authors use a manometer - tube in the form of letter $U$ containing colored fluid. Correctly using the PYT technique, and creating negative pressure, the fluid in the manometer comes towards the nostril and flows away generating positive pressure ${ }^{(17)}$. From our experience, at the initial learning phase, it is difficult for the patient to control the colored fluid in the manometer. It often spills out of the tube causing aspiration and contamination of the working place, which is not the case with rhinomanometry. Other authors tried to enhance the success of rehabilitation by videotaping the patient while performing PYT. The registered videotape is analysed by the physician and speech therapist and possible mistakes are pointed out to the patient ${ }^{(20)}$. 
Our results of olfactory rehabilitation using PYT were slightly poorer $(40 \%$ vs. $46 \%)$ compared with the results of other investigations ${ }^{(8)}$. One probable reason could be the short individual training period ${ }^{(20,21)}$. As all the patients were members of the Laryngectomised patients Club, we intended to introduce group training of PYT during their meetings. The aim was for PYT to become standard practice, which could be applied in everyday use with expert advice and patients' consent.

\section{CONCLUSION}

The application of rhinomanometry substantiates the evaluation of postlaryngectomy olfactory rehabilitation. Explaining the method to the patient is simplified by presenting a chart of nasal flow generation in relation to the movement of PYT that is being carried out. The curves and volume of air seen on the monitor of the rhinomanometer give direct visual feedback. PYT has proved to be an effective method in olfactory rehabilitation. The importance of olfactory rehabilitation should not be underestimated and should be carried out as an integral part of the postlaryngectomy rehabilitation programme.

\section{ACKNOWLEDGEMENTS}

We wish to acknowledge the cooperation of "Klub laringektomiranih PGŽ" and all our patients without whom these studies would not have been possible. We are also grateful to professor Frans Hilgers from the University of Amsterdam for his critical review of the manuscript.

\section{REFERENCES}

1. Miwa T, Furukawa M, Tsukatani T, Constanzo RM, DiNardo LJ, Reiter ER. Impact of olfactory impairment on quality of life and disability. Arch Otolaryngol Head Neck Surg. 2001; 127: 497503.

2. Van Dam FSAM, Hilgers FJM, Emsbroek G, Touw FL, van As CJ, De Jong N. Deterioration of olfaction and gustation as a consequences of total laryngectomy. Laryngoscope. 1999; 109: $1150-1155$.

3. Hilgers FJM, Ackerstaff AH, Aaronson NK, Schouwenburg PF, Van Zandwijk N. Physical and psychosocial consequences of total laryngectomy. Clin Otolaryngol. 1990; 15: 421-425.

4. Ackerstaff AH, Hilgers FJM, Aaronson NK, Balm AJM. Communication, functional disorders and lifestyle changes after total laryngectomy. Clin Otolaryngol. 1994; 19: 295-300.

5. Hilgers FJM, van Dam FSAM, Keyzers S, Koster MN, van As CJ, Muller MJ. Rehabilitation of olfaction after laryngectomy by means of a nasal airflow-inducing maneuver: the «polite yawning» technique. Arch Otolaryngol Head Neck Surg. 2000; 126: 726-732.

6. Risberg-Berlin B, Moller RY, Finizia C. Effectiveness of olfactory rehabilitation with the nasal airflow-inducing maneuver after total laryngectomy: one-year follow-up study. Arch Otolaryngol Head Neck Surg. 2007; 133: 650-654.

7. Dessi P, Sambuc R, Moulin G, Ledoray V, Cannoni M. Effect of heavy smoking on nasal resistance. Acta Otolaryngol. 1994; 114:
305-310.

8. Hilgers FJM, Jansen HA, van As CJ, Polak MF, Muller MJ, van Dam FSAM. Long-term results of olfaction rehabilitation using the nasal airflow-inducing ('Polite Yawning') maneuver. Arch Otolaryngol Head Neck Surg. 2002; 128: 648-654.

9. Suzina AH, Hamzah M, Samsudin AR. Objective assessment of nasal resistance in patients with nasal disease. J Laryngol Otol. 2003; 117: 609-613.

10. Clement PA, Gordts F. Standardisation Committee on Objective Assessment of the Nasal Airway, IRS, and ERS. Consensus report on acoustic rhinometry and rhinomanometry. Rhinology. 2005; 43: 169-179.

11. Hirschberg A, Roithmann R, Parikh S, Miljeteig H, Cole P. The airflow resistance profile of healthy nasal cavities. Rhinology. 1995; 33: 10-13.

12. Vogt K, Jalowayski AA. The objective and measurement principles of rhinomanometry. Rhinology. 2010; 48 Suppl 21: 5-6.

13. Maranta CA, Scherrer JL, Simmen D. The mask: style and volume do not influence rhinomanometry. Rhinology. 1995; 33: 84-85.

14. Simmen D, Briner HR, Hess K. Screeningtest des Geruchssinnes mit Riechdisketten. Larygorhinootologie. 1999; 78: 125-130.

15. Briner HR, Simmen D. Smell diskettes as screening test for olfaction. Rhinology. 1999: 37: 145-148.

16. Brämerson A, Johansson L, Ek L, Nordin S, Bende M. Prevalence of olfactory dysfunction: the skövde population-based study. Laryngoscope. 2004; 114: 733-737.

17. Morales-Puebla JM, Morales-Puebla AF, Jiménez-Antolín JA, Muñoz-Platón E, Padilla-Parrado M, Chacón-Martínez J. Olfactory rehabilitation after total laryngectomy. Acta Otorrinolaringol Esp. 2010; 61: 128-134.

18. Naito K, Iwata S. Current advances in rhinomanometry. Eur Arch Otorhinolaryngol. 1997; 254: 309-312.

19. Hirschberg A. Rhinomanometry. An update. ORL J Otorhinolaryngol Relat Spec. 2002; 64: 263-267.

20. Risberg-Berlin B, Ryden A, Ylitalo Moller R, Finizia C. Development of a clinical instrument improving rehabilitation of olfaction with the Nasal Airflow-Inducing Maneuver in Swidish laryngectomized patients. Acta Otolaryngol. 2009; 129: 1026-1032.

21. Ward E, Coleman A, van As-Brooks C, Kerle S. Rehabilitation of olfaction post-laryngectomy: a randomised control trial comparing clinician assisted versus a home practice approach. Clin Otolaryngol. 2010; 35: 39-45.

22. Moor JW, Rafferty A, Sood S. Can laryngectomees smell? Considerations regarding olfactory rehabilitation following total laryngectomy. J Laryngol Otol. 2010; 124: 361-365.

Dubravko Manestar

Department of Otorhinolaryngology,

Head and Neck Surgery

Clinical Hospital Centre Rijeka

Krešimirova 42

51000 Rijeka

Croatia

Tel: +385-(0)51-658 161

Fax: +385-(0)51- 624372

E-mail: dubravko_manestar@net.hr 